\title{
ESTAR - COM os pais em seu vivenciar a doença do filho - uma perspectiva fenomenológica *
}

\author{
Jane Cristina Anders **
}

\begin{abstract}
RESUMO - Nesse estudo propusemo-nos a des-velar facetas do significado de vivenciar a situação de doença grave de um filho, aos olhos de seus pais. Dada a natureza desse objetivo de estudo optamos pela metodologia de investigação fenomenológica que permite o acesso a esses pais no seu ver e sentir o cuidado com o filho gravemente enfermo. Coletamos depoimentos de pais que estão vivenciando essa situação e que se dirigiam a um Ambulatório Regional Especializado (SUDS) para buscar uma guia que concedesse o tratamento quimioterápico para seus filhos. A análise de suas falas, segundo os passos da metodologia fenomenológica, possibilitou o des-velamento de facetas que expressam a essência desse experienciar e que abre caminhos para nortear a assistência de enfermagem que contemple a complexidade da situação desses pais no seu estar-com o filho doente.
\end{abstract}

\begin{abstract}
The objective of the present study was to reveal different aspects of what it means to parents to experience a situation of severe ilIness of one of their children. In view of the nature of this type of study, we've chosen the phenomenological methodology of perception of, and feelings about, the care of a severely ill child. We've obtained declarations from parents in this situation when they sought a Specialized Regional Ambulatory (SUDS) to obtain a form that would grant chemotherapy for their children. Analysis of speech of these parents according to the steps of the phenomenological methodology have permitted us to uncover facets that express the essence of this experiencing and that open the way for the establishment of guidelines for a type of nursing care that considers the complexity of the situation of these parents as they experience the situation of having a severely ill child.
\end{abstract}

\section{INTRODUÇĀO}

Surgindo a possibilidade de participar do projeto de pesquisa "Estudos fenomenológicos da morte e do morrer" passei a realizar uma busca na literatura sobre estudos referentes a este tema, o qual foi-se mostrando a mim, nesse meu caminhar, como um tema rico e inquietador.

Paralelamente às leituras, o desenrolar de minhas experiências enquanto aluna de enfermagem possibilitou-me observar a grande inquietação que a temática da morte provoca nos profissionais da área da saúde.

As leituras que pude realizar possibilitaram-me entender que as atitudes do homem diante da morte mudaram profundamente através dos séculos, ocorrendo rupturas no pensar, no entender e no encarar a morte ao longo da História. Pude também perceber que o tema precisa ser analisado sob várias perspectivas: da História, da Sociologia, da Psicologia, da Filosofia. São essas várias perspectivas que podem nos levar a uma compreensão mais global do fenômeno MORTE.

Procurei direcionar meu trabalho para os pais de crianças doentes considerando que meu interesse pelo assunto crescia acentuadamente, configurando-se enquanto uma inquietação que passa a exigir respostas.

\footnotetext{
* Prêmio Marina de Andrade Rezende - 1․ Lugar - 43 Congresso Brasileiro de Enfermagem - Curitiba, PR. 1991. Trabalho realizado sob orientação da Profa Magali Roseira Boemer

** Aluna do Curso de Graduação em Enfermagem da Escola de Enfermagem de Ribeirão Preto - USP. Bolsista do Programa de Iniciação Científica do CNPq
} 
O meu tempo vivido enquanto aluna de enfermagem tem me possibilitado compartilhar de situações de perdas vivenciadas por familiares quando um ente querido se aproxima de sua terminalidade. Essas situações geram grande desconforto para aqueles que habitam o mundo do hospital.

Esse vivenciar levou-me a um interrogar a situação dos pais da criança gravemente enferma pois, apesar das leituras dos vários estudos nesse sentido, algo continua obscuro para mim. Os momentos dedicados ao levantamento da literatura e o meu vivenciar a morte nos estágios suscitaram-me a necessidade de um olhar mais atentivo nessa direção.

Compreender os pais no seu estar-com o filho gravemente enfermo passa a ser minha proposta de trabalho e, nessa postura, a metodologia de investigação fenomenológica se me apresenta enquanto possibilidade de acesso a esse "objeto" de estudo.

Assim, este estudo se propõe à compreensão dos pais nessa situação segundo os passos do método fenomenológico cujas idéias básicas exponho na metodologia.

\section{METODOLOGIA}

\subsection{Fundamentaçāo Metodológica}

O presente trabalho foi realizado segundo a metodologia de investigação fenomenológica 4,5 . De coriformidade com esta metodologia foi fundamental ir ao sujeito que experiência a situação que nos inquieta - os pais de crianças gravemente enfermas - ouvindo a sua fala, o seu dizer sobre como isso se mostra a eles, em suas existências. Nesse caminho vislumbro a possibilidade de compreensão dos pais no seu vivenciar a doença do filho.

\subsection{Seleçāo do Local}

$O$ estudo foi realizado no Ambulatório Regional Especializado (ARE) do SUDS - ERSA -50 , considerando que é para esse setor que os pais se dirigem a fim de obterem a guia necessária para que a criança que necessita de tratamento quimioterápico possa realizá-lo.

Essa circunstância tornou possível meu acesso aos pais no momento em que se dirigem ao referido ambulatório na busca da guia para o tratamento da criança.

Contei com o apoio do Serviço para realizar o trabalho no sentido que os pais, após obterem as guias, fossem encaminhados a mim. Foi possível dispor de uma sala privativa, imprescindível para a realização do encontro.

Os encontros foram realizados no período da manhã, nos meses de dezembro de 1990 a fevereiro de 1991.

\subsection{Encontros com os pais}

Quando cada pai ou mãe ou responsável chegava a sala, expunha a minha situação de aluna do Curso de Enfermagem e o meu interesse em saber dos pais o significado de estar experienciando um momento de doença do filho, que requer tratamento sério e prolongado. Solicitava sua colaboração em falar sobre essa sua experiência, se o desejasse, e assegurava seu anonimato. Iniciava então, a entrevista conduzida de acordo a abordagem fenomenológica, segundo a qual um encontro existencial acontece entre pesquisador e sujeito.

Não havia roteiro a ser seguido e nenhum limite de tempo. Elaborei uma questão orientadora que propunha aos pais de forma a orientar a sua fala.

- Questāo Orientadora: “O que está significando para o Sr. ou a Sra. estar vivenciando o processo de doença de seu filho?"'

Uma vez proposta a questão, me colocava na situação de ouvinte, à escuta do seu discurso, da sua fala. Fala entendida como manifestação do ser. Optei por não usar o gravador por entender que ele poderia inibir sua fala ou mesmo se apresentar como algo agressivo e especulativo aos olhos dos pais.

Após cada pai ou mãe fornecer o seu depoimento redigia o relato do encontro procurando relatá-lo tal qual havia ocorrido, dentro dos limites humanos dessa possibilidade.

Desta forma, só após transcrever um encontro é que estava disponf vel para iniciar um outro.

Em algumas ocasiões permaneci no local por várias horas esperando pelos pais. Isto nem sempre ocorria já que a frequência deles ao ambulatório não obedece a uma regularidade, estando ligado a necessidade terapêutica.

Os encontros apresentaram-se a mim como fonte de desvelamentos, de novos velamentos, de novas interrogações, de angústia e de compartilhamento.

Coletei dezoito depoimentos nesses encontros, cujos relatos encontram-se em minha posse'.

\section{APRESENTAÇĀO E ANÁLISE DOS DADOS}

Durante o perfodo de coleta de dados foi possível realizar dezoito encontros com pais (mãe ou pai) ou responsável de crianças com Câncer, quando estes se dirigiam ao Ambulatório Regional Especializado, conforme já foi mencionado.

Cabe dizer aqui que a maioria desses pais procede de Ribeirão Preto e, principalmente, da região abrangida pelo ERSA 50. Encontramos dois desses pais que procediam do Estado de Minas Gerais.

1 No presente trabalho os núm us entre parênteses, referem-se aos respectivos depoimentos. 
Desses dezoito encontros, doze foram realizados com a mãe, quatro com o pai, um com a madrinha da criança e um com uma amiga da família. Alguns não mencionavam o diagnóstico da criança, mas o mesmo constava na guia para quimioterapia que era trazida por eles.

Uma vez coletados os depoimentos passamos à sua análise segundo os passos da metodologia qualitativa, de acordo com MARTINS, BICUDO4.

\section{- Uma Experiência cuja Trajetória é Diffcil}

A doença envolve um longo caminho a ser percorrido pelos pais, onde o início da doença é entendido por eles como um momento mais difícil.

Ainda que as dificuldades especifficas decorrentes do tratamento que envolve e altera toda a dinâmica familiar sejam destacada, o momento do início da doença se superpõe à essas dificuldades que surgem posteriormente.

Esse momento de início da moléstia emerge de forma muito presente nas falas dos pais. Embora o tempo decorrido entre esse início e o momento da entrevista tenha sido variável, uma vez que entrevistamos pais cujos os filhos estavam em diferentes fases de evolução da moléstia, o que se percebe é que o início é sentido como o momento mais doloroso.

Há de se notar nos depoimentos que eles contemplam essa temporalidade da moléstia: o surgir, o lidar com ela, e a perspectiva futural de vencê-la.

Vejamos algumas falas que revelam essa percepção dos pais:

"No começo foi muito difícil. Passamos por desespero, momentos de desânimo". (1)

Para as mães que referem estar sozinhas nesse vivenciar, a dificuldade desse momento se reveste de importância, segundo seus depoimentos. Cabe ressaltar que essas mães não falaram dos motivos desse sentir-se sós.

"Foi uma agonia, principalmente quando a gente é sozinha". (6)

"Eu sou sozinha e segurar essa barra sozinha não é fácil”'. (15)

Esse início da moléstia se configura como um momento muito difícil e cabe aqui algumas considerações sobre o seu significado: é o momento em que as preocupações se iniciam e, em geral, os primeiros sinais e sintomas surgem abruptamente, levando os pais a procurar assistência médica.
"A doença surgiu de uma hora para outra". (6)

"Eu levei meu filho ao médico porque ele tava pálido e de repente a doença". (16)

A procura pelo profissional médico foi relatada como tendo ocorrido logo no início da moléstia.

Sucessivos encaminhamentos médicos também são relatados sugerindo uma trajetória longa até o diagnóstico atual. Sucessivas buscas por profissionais médicos também são relatados na medida em que os pais, inseguros diante de um diagnóstico médico e percebendo a piora do filho buscam muitas especialidades na tentativa de elucidar a doença.

$\mathrm{O}$ tempo decorrido entre os primeiros sinais e sintomas e o diagnóstico atual é muito presente também em suas falas, conforme podemos observar:

"Levamos nosso filho a mais ou menos quinze médicos diferentes. Depois de muitos diagnósticos falsos, como: seu filho terá apenas cinco anos de vida foi encontrado que meu filho tem um tumor maligno (na altura do rim perto do intestino) mas com $70 \%$ de chance de recuperação". (2)

"Tratei dois meses de reumatismo. Faz um mês que descobriram a doença". (5)

Os primeiros sintomas apresentados pelo filho tamberm estão muito presentes nas memórias dos pais que contam, com detalhes, esses sintomas e como foram por eles percebidos como preocupações carecendo de assistência médica.

"A doença apareceu com dores no joelho"'. (5)

"A criança começou a ter dores no esterno, depois a dor foi para a coluna e cólicas no abdomén". (7)

Acompanhando essa trajetória do vivenciar dos pais observa-se que algumas interrogações são levantadas por eles na procura de um entendimento, explicação da doença do seu filho, entendimento esse, que é permeado por tentativas de aceitar a doença. Essa aceitação, quando ocorre, é contornada de momentos de revoltas quando os pais procuram razões para o que lhes está acontecendo. Para os pais torna-se muito importante a procura desse entendimento para a realização do difícil tratamento da doença do filho.

"Quando fui ao médico, ele disse que não adiantava eu querer uma explicação 
da doença que ele não teria jeito de explicar como a doença surgiu". (5)

"O médico me disse que essa doença é um vírus que todo mundo tem e de repente ele se manifesta. A gente tem que acreditar no que o médico diz". (8)

Essa faceta do vivenciar dos pais que se mostrou a nós, nos leva a pensar numa assistência a esses pais que contemple a dificuldade particular do início da doença. Seus depoimentos permitem observar que há expectativa de ajuda de sua parte, ajuda essa que remete a possibilidade de ser ouvido em suas dúvidas, revoltas, indagações, inquietações.

\section{- Permeado de preocupaçōes e cuidados advindos da Terapêtica Médica}

Como já relatamos, os depoimentos foram coletados no Ambulatório Regional Especializado no momento em que os pais ar se dirigiam para buscar guia para quimioterapia. Assim, quando os pais se referem ao tratamento estão fundamentalmente se referindo à quimioterapia, que conforme salienta LIMA $^{3}$ em seu estudo realizado em Ribeirão Preto, é a terapêutica mais utilizado nos casos de Câncer infantil de uma maneira geral.

O tratamento quimioterápico tem particularidade que a criança e a famnlia devem ter conhecimento. Nesse sentido a orientação é essencial no enfrentamento das dificuldades que envolvem a adaptação e ajustamento a uma nova imagem corporal devido a perda de cabelos e edemas, ef eitos colaterais os quais podem ser de origem fisíca e ou emocional a depender da droga utilizada e das características individuais dos pacientes.

BOEMER, VALLE' em seu estudo com enfermeiras pediátricas que cuidam de crianças com Câncer, identificam a quimioterapia como uma faceta do tratamento de grande relevância na interação enfermeiro-criança, pelo que ela representa em termos de agressão e desconforto sentidos pela criança e que envolve o enfermeiro que em geral é quem ministra o tratamento.

LIMA $^{3}$ salienta em seu estudo que a assistência à criança com Câncer vem sof rendo transformações. A terapêutica, a patologia e o diagnóstico, ou seja, a atenção com o corpo biológico, eram considerados os pontos principais e que mostra-se agora insuficiente para atender às necessidades de integralidade apresentadas pelas crianças com Câncer e suas famílias.

O que evidencia-se nas falas dos pais é uma grande preocupação com a quimioterapia enquanto uma das modalidades terapêuticas. Preocupação esta que não se restringe apenas às questões técnicas da administração do medicamento.

Denominam esse tratamento como um processo que passa a exigir muito deles por este ser considerado uma terapêutica delicada e com muitos cuidados. Cuidados estes que necessitam grandes esforços dos pais, onde passam a iniciar uma trajetória muito longa e com um único intuito: a cura do filho.

Seus dias passam a ser cheios de incertezas e inseguranças quanto ao bom andamento do tratamento, e este passa a exigir horários, cuidados higiênicos e alimentares.

Os contatos com outras pessoas são bastante controlados pelos pais, para evitar infecções a seu filho.

"Quando os membros da família saem de casa, antes de entrar em contato com o garoto têm que lavar as mãos e tomar banho". (5)

"Cibele não pode ocupar o banheiro do hospital por perigo de infecção". (7)

A preocupação com o horário das medicações também aparecem em suas falas como de fundamental importância. Podemos observar em algumas falas:

"Só penso em levar a sério o tratamento (dar os remédios, fazer quimioterapia)". (4)

"Os horários dos remédios é uma religião para mim”. (10)

Os medicamentos utilizados nesse tipo de tratamento envolvem características muito particulares e específicas, pois estes são entendidos como muito "fortes" e alteram a resistência da criança. Vejamos algumas falas:

"As medicações derrubam". (1)

"Quando a resistência cae fica difícil".

(8)

A análise dos depoimentos permite ainda observar que os pais, em geral, apresentam outras dificuldades para realizarem o acompanhamento médico do filho. A locomoção já que muitas famńlias são de outras cidades somada a preocupação com o alto custo do tratamento são particularidades da trajetória percorrida pelos pais e o filho doente, conforme emerge em suas falas.

"Tivemos que viajar muito atrás de médicos e exames. Foi gasto muito dinheiro. Sou de famnia pobre". (2)

"Eu moro em São José do Paraíso e tenho que pegar dois ônibus, fica diffcil"'. (4) 
Nos encontros os pais relatavam que seus filhos são assistidos por um médico que os acompanha desde o início do tratamento e pelos profissionais do posto de saúde e do hospital. $\mathrm{O}$ atendimento do hospital é dividido pelos pais em dois momentos diferentes: quando seu filho recebe o tratamento de quimioterapia e quando está internado.

Os profissionais de saúde são avaliados pelos pais segundo suas práticas, com suas disponibilidades para atenderem seu filho e segundo os sentimentos que eles têm pela criança em seu cuidar. As falas dos pais permitem ver essa avaliação:

"A enfermeira tem muita paciência, cuida da Gabriela direitinho (quimioterapia)". (10)

"Tenho que ir lá até às 11:00 horas senão a moça vai embora". (3)

Os pais enfrentam uma grande rotatividade para realizar esse tratamento pois têm que se deslocar de um lado para outro num mesmo perfodo e em sucessivos momentos do dia. Com todas essas questões que permeiam a realização dessa terapêutica e por se tratar de uma assistência direcionada à criança existe um aspecto do cuidado que se revela ao profissional nessa difícil terapêutica. Esse aśpecto é o que não permite olhar apenas para a moléstia mas sim para a criança doente.

O profissional de saúde foge das habilidades técnicas, apenas, e busca assistir essa criança e sua famnia de uma forma mais humana e compreensiva. Por perceberem esse envolvimento os pais expressam uma imensa gratidão pela equipe de saúde.

"Eles entendem o que estamos passando". (5)

"O paciente está no hospital para sarar

e a enfermeira dá apoio e ajuda a quem

precisa". (10)

Por outro lado os pais se chocam muito quando existe por parte desse profissional uma atitude agressiva e pouco compreensiva. Podemos analisar em uma das falas:

"Uma vez um médico foi estupido apenas porque queria trocar de horário".

As falas nos revelam que a figura do médico é muito presente na medida em que a terapêutica e, portanto, a possibilidade de cura, dele dependerá.

Um tratamento com tantas particularidades e que exige tantas disponibilidades leva a fami- lia a mudar seus costumes e sua rotina, dessa forma suas vidas sof rem fortes mudanças. Os discursos dos pais nos mostram essas mudanças no âmbito profissional, financeiro, sentimental e pessoal.

"Agora não dá mais para a esposa trabalhar fora". (1)

"Com a doença do filho o pai até voltou para casa". (6)

“Nós quase não saimos mais". (7)

Em outros encontros foi muito presente a expectativa dos pais visando sarar sua criança acima de qualquer obstáculo:

"O que importa agora é sarar a filha". (8)

"Tentei mostrar para meu marido que não adiantava gritar que agora tinha que sarar Gabriela". (9)

Estamos diante de uma terapêutica que vem a exigir muito desse ser com seu filho doente. Toma-se necessário que todas as pessoas que compartilhem com essa famlia as ajudem com seus pequenos gestos de apoio e carinho, ao lado da assistência na dimensão profissional suavizando assim essa difícil trajetória percorrida pelos pais.

\section{- Com Disponibilidade para assumir o cuidado do Filho}

O cuidar de crianças doentes assume uma dimensão compreensiva do ser criança que transcende ao tratamento de sua doença. Um cuidado compreensivo, incluindo atenção às necessidades emocionais e sociais se reveste de extrema importância para o tratamento da criança grave, onde esta encontra-se em fase de crescimento e desenvolvimento.

A assistência à criança com Câncer implica em períodos de hospitalização intercalados com atendimento ambulatorial. Nos momentos de internação é essencial a presença de um elemento da famnlia acompanhando-a. Nessa forma, a assistência deve contemplar não apenas à criança doente mas tamberm as especificidades da familia.

LIMA $^{3}$ nos aponta que a hospitalização de crianças com Câncer tem algumas características que as distinguem de outras na unidade de internação, pois estes tem geralmente um prognóstico reservado pela cronicidade da doença, as internações são frequentes, os traumatismos físicos e psiquícos que a criança sofre pela terapêutica agressiva e a alta mortalidade com repercussões sérias na famflia. Toda essa problemática acarretou modificações na as- 
sistência dessas crianças.

KNUDSON, NATTERSON ${ }^{2}$ referem-se à importância da farnnlia no cuidado da criança hospitalizada, portadora de Câncer.

No ver da famf́lia, esse cuidar envolve muitos sentimentos como: carinho, compreensão, medos, inseguranças, esperança. Ocorre também uma tendência a buscar apoio em crenças e na força da religião.

Podemos observar que essas facetas se mosam nos encontros com os pais:

"Para cuidar de crianças doentes sugiro paciência, muita paciência". (1)

"Sabe acredito muito na religião, nằo acho que alguém paga os pecados com a doença. Tenho fé que um dia não vai existir doenças, médicos e nem hospitais". (2)

Todos esses momentos vivenciados pelos pais são permeados por uma grande expectativa de um possível final de tratamento onde se localiza a esperança da cura:

"Não vejo a hora de acabar com os medicamentos". (6)

"Em Maio ele termina o tratamento". (10)

A insegurança e a incerteza estão presentes durante todo o evoluir da moléstia mesmo quando as respostas ao tratamento são positivas os pais sentem esses sentimento. Abrangem tamberm o receio de uma volta da doença.

Segundo VALLE ${ }^{6}$, em estudo realizado com os pais de crianças com Câncer, o tratamento da criança portadora dessa moléstia representa para a famflia períodos de otimismo e esperança permeados por outros de maior desestruturação e forte ameaça de perda.

"Mesmo vendo que o tratamento está indo bem a gente fica com o coração na mão". (8)

"Só tenho medo que todo esse sacrificio não dê em nada e que a doença volte". (14)

Esses sentimentos são permeados também pelo receio de que seus outros filhos adquiram essa doença. Vejamos essa preocupação na fala de uma mãe:

"Tenho medo que minha filha mais nova também tenha essa doença, ar vai ser mais diff́cil, a gente tem medo disso". (14)

Os pais, no seu co-existir com o filho doente passam a imergir nessa interação de forma que seu mundo de relações com o filho passa a ser de um mundo compartilhado. Suas existências passam a ser voltadas para o filho, não parecendo haver espaços para ser eles mesmos. Seu pensar, seu conviver e seu ouvir passam a se voltar exclusivamente para a moléstia do filho.

Nesse sentido, nosso encontro com esses pais mostrou-se a eles enquanto oportunidade de verem-se a si mesmos nessa experiência.

Cada encontro que mantivemos com os pais ou responsáveis de uma criança doente foi envolvido por fortes emoções. Analizando todas as facetas abrangidas por esse cuidar torna-se muito clara a importância de se ouvir os pais em suas expressões. Assim é que nos encontros que mantivemos eles abordavam essa necessidade e agradeciam a oportunidade de estarem conversando sobre o seu vivenciar. Essas oportunidades foram percebidas pelos pais como muito importantes e lhes possibilitava expressar o seu vivenciar, implicando num auxnlio para o seu caminhar ao lado do filho.

Vejamos algumas falas nesse sentido:

"É muito importante ter ajuda das pessoas nessas horas". (4)

"Está sendo muito bom desabafar um pouco". (5)

Em dois encontros realizados, um com a mãe e outro com a madrinha de uma criança doente, ambas optaram por não conversar naquele momento sobre essa sua experiência. Vejamos essas falas:
"Rosana tem Leucemia e é só". (13) - Madrinha da criança
"Olha eu preferia não falar. Se fosse uma coisa simples eu conversaria com o maior prazer. Falar ia me emocionar e ficar descontrolada psicologicamente". (15) - Mãe da criança

Também houve mães que retornaram em outros momentos para conversar, uma vez que eu dissera que ali estaria durante um determinado período. Às vezes voltavam para conversar conosco, trazendo seu filho doente para que os conhecessemos. Houve também ocasião em que a mãe, em determinado momento do encontro expressa a vontade de sair da sala para buscar seu filho para que pudéssemos conhecê-lo.

Isto nos sugere um relacionamento empático em que nos mostramos a ela num movimento de compartilhamento, num estar-com. Suas falas expressam esses momentos:

"Se eu soubesse que iria conversar com você teria trazido a Gabriela para conhecer, ela é loirinha". (9) 
“Aquele é meu filho Carlos". (16)

Esse vivenciar assume perspectiva de compartilhar com os pais nesse momento, porém, é encarado pelos pais como uma situação que só existindo com um filho doente para entender como é um caminhar que remete a dificuldades.

Podemos ver na fala de uma mãe:

"Por mais que as pessoas imaginem como é ter uma pessoa com Câncer, só vivenciando essa experiência para saber como é difícil"'. (5)

Até então, as falas dos pais permitem-nos ver como os pais vêm as facetas que envolvem seu vivenciar o cuidar de seu filho. Há, entretanto em suas falas, outros momentos que permitem analisar como os pais vêm o seu filho doente e esse ver implica em seu vivenciar a doença do filho. Assim, passamos a outra categoria que procura evidenciar como suas falas se referem a como vêm o filho doente.

\section{- Uma experiência que lhes impōe uma visāo do Filho diante da Doença e do Tratamento}

Sendo seu filho portador de uma grave doença e tendo que submeter-se a um difícil tratamento com toda sua agressividade, os pais expressam muitos sentimentos de pena, chegando mesmo a colocarem-se no lugar do seu filho doente:

"Elas têm que pensar que é difícil para

a criança fazer esse tratamento". (2)

“Dá dó, é tão pequenininho". (12)

Diante desse tipo de terapêutica é natural que ocorra a aceitação ou a recusa dos filhos em realizar esse tratamento que devido as suas especificidades assustam os pais:

"No início foi difícil fazer a criança tomar os remédios". (1)

"A criança aceitou os remédios sem problemas". (4)

Em um determinado momento do tratamento a criança se defronta com a questão da aparência devido aos efeitos colaterais. Nem em todas as falas dos pais essa questão é encarada como problema para seu filho:

"A criança não gostou quando o cabelo caiu". (1)

"No iń́cio quando ela ficou inchada, ficou com complexo". (7)

VALLE $^{6}$ em seu estudo com pais de crianças com Câncer salienta que as conseqüências advindas do tratamento acarretam sof rimento para a criança e dispertam um olhar compreensivo dos pais, quando procuram compartilhar com o filho o seu sofrimento. Nesse estar - com - o - filho os pais chegam a raspar seu próprio cabelo não o deixando crescer, enquanto também não crescer o cabelo do filho.

Durante esse percurso os pais se deparam com toda a dinâmica que envolve essa terapêutica. As relações que mantinham com as outras famnias realizando o mesmo tipo de tratamento permitiam que os pais comparassem "seu filho" com outras crianças, na perspectiva de que o tratamento estava apresentando maiores chances de cura para "seu filho". Os pais compreendem que a criança também apresenta essa percepção:

"Outras crianças tomam seis comprimidos por dia e meu filho quatro por dia".

(1)

"Meu filho e mais corado e tem mais energia para brincar”. (2)

Para algumas crianças a realização desse tratamento acarretou mudanças nas suas vidas. Porém as mudanças não demonstram muita gravidade para alguns pais e para outros os filhos não aceitam essas mudanças:

“Jusepen sempre ficava no portão e as pessoas conversavam com ele. Explico para ele que tem que ficar em casa para sarar e não pegar nenhum bichinho na rua". (2)

"Leandro é um pouco revoltado porque no começo não podia deixar ele sair na rua". (11)

A disponibilidade do filho em realizar o tratamento, sua "força de vontade" auxiliam muito os pais nesse caminhar e um pequeno gesto ou elogio do filho torna-se essencial para os pais:

"Meu filho diz que sou uma mãe muito divertida e que os amigos dele falam que sou super legal". (6)

"Meu filho tem a cabeça muito boa, pensei que iria me dar trabalho, mas não, muito pelo contrário. Ele tem muita força de vontade". (16)

$\mathrm{Na}$ tentativa de acreditar que seu filho está melhorando, os pais procuram compará-los com o momento do início do tratamento.

\footnotetext{
"Hoje meu filho é forte e bonito, antes era inchado e fraco". (6)

"Quando trago André no H. Santa Lidya onde ele ficou internado a enfermeira que cuidou dele não acredita que é o mesmo". (16)
} 
Muitos pais preocupam-se em esconder a doença do filho enquanto outros encaram como fator positivo o mesmo conhecer o "nome" da doença.

"Escondo a doença do meu filho, mas meu marido ressalta que o garoto sabe do problema e diz: Você acha que Adriano não percebe que tem Câncer". (6)

"O pai é que não queria que ela soubesse e quando ela ficou internada o pai mentia sobre a doença e a Flávia falava: "Pai eu sei que não é isso, eu tenho Leucemia". (8)

Diante da facticidade do seu filho os pais assumem a perspectiva de cura, mesmo diante de dificuldades e inseguranças. Apenas uma mãe refere que estão vivendo uma situação onde a morte pode ser uma nova experiência.

"Eu şei que essa doença pode levar meu filho a morte". (16)

\section{- Uma experiência que afeta o seu existir - com os outros filhos}

O filho doente exige uma decisão dos pais, pois requer muita atenção. A doença da criança pode afetar o seu relacionamento com os irmãos, alterando portanto o existir dos pais no seu sendo com, os outros filhos, podendo dar, surgir momentos de conflito e de ciúmes. Diante disso os pais procuram entender a situação e compreender seus filhos, não os culpando.

"O grande tempo que eu e meu marido gastamos em levar Cibele ao hospital acarretou dificuldades na minha filha menor". (7)

"Eles ficam com ciúmes e eu explico que Gabriela tem problemas”. (9)

A tarefa educativa, os sentimentos como amor, carinho e atenção preocupam os pais na sua interação com todos os filhos. Em outras falas existe também a verbalização de um relacionamento bom, pois "a doença não acarretou nenhum problema”.

"Quando minha mulher está com Felipe no colo, fico brincando com os outros dois, me preocupo muito com a recreação deles". (2)

"Procuro dar carinho aos três ao mesmo tempo". (9)

As falas dos pais nos revelam as dificulda- des que vivenciam com os outros filhos e a sua perspectiva de ajuda interagindo nessa situação.

O vivenciar dos pais abrange preocupações inerentes a toda a famnlia no existir com um ente querido diante de toda a complexidade que envolve seu Ser-com-o-filho gravemente enfermo.

\section{CONSIDERAÇŌES FINAIS}

Tentei, neste estudo, encontrar uma forma de acesso ao mundo dos pais que convivem com a situação de ser no mundo com sua criança enferma, através da análise atentiva de suas falas.

Os encontros que mantivemos foram permeados por momentos em que nos defrontamos com o seu vivenciar, entendidos por nós como uma longa trajetória que requer muito do ser desses pais na sua facticidade com seu filho doente. Esses momentos foram envolvidos por fortes emoções nos levando a sentimentos inquietantes, por partilhar dos seus sofrimentos. Foram momentos dolorosos, mas que, por outro lado, foram muito gratificantes no sentido de, estar proporcionando condições para que os pais pudessem expressar-se naquilo que se mostrava importante para eles. Alguns manifestavam-se mais espontaneamente que outros, chegando a expressar emoções muito intímas do seu ser.

Diante de toda essa temática que envolve o vivenciar dessas pessoas torna-se necessário uma nova perspectiva de cuidar. Ocorre a necessidade dos profissionais de saúde assistirem essas crianças sob a perspectiva de sua situcionalidade, como um ser doente e sua família.

Apesar dos pais estarem vivenciando momentos em que a morte pode ocorrer, eles evitam o defrontar-se com a finitude do filho.

Entendo, mesmo com minha pouca experiência no cuidar de crianças, que eles merecem de todas as pessoas um olhar mais atento no sentido de estarem proporcionando um vivenciar onde não se sintam sozinhos em sua trajetória.

- O desvelamento das facetas desse vivenciar abre alguns caminhos para a assistência de enfermagem - criança doente, que contempla o sentir dos pais, o seu ver o filho gravemente enfermo. Nesse sentido parece-nos relevante atentar para a trajetória que percorrem desde o início da doença e na qual o início assume relevância em suas falas. Propostas de sistematização de assistência de enfermagem precisam estar atentas a esse momento que se revelou de forma particularmente difícil para os pais. Ainda vemos que essas pessoas com o seu estar disponível para o cuidar do filho representam um aliado importante no plane jamento dessa assistência e pode co-deterninar com os enfermei- 
ros as formas de cuidado da criança.

Outra faceta desvelada e que diz respeito ao seu ver o filho diante da doença e do tratamento possibilita-nos entender a relevância de sua co-participação no cuidado na medida que expressa que apreendeu o seu filho, e nessa apreensão está contida uma compreensão.

Seu vivenciar a doença do filho permite-lhe ver que toda sua família está envolvida e de forma particular, ela se volta com preocupação para os outros filhos por percerber que eles ficam privados da atenção dos pais. Ela também apreende e compreende esse sentir e sofre por ele.
Esse conviver com os pais e a análise dos depoimentos nos indicam que novos horizontes precisam ser buscados no que tange à assistência de enfermagem à criança gravemente doente e que contemplem a perspectiva dos pais. Há de se ressaltar que esse tema vem merecendo a atenção de autores brasileiros conforme expussemos no decorrer deste trabalho. Muito já foi feito e muito há de fazer. Parece-nos entretanto, a partir dos resultados deste estudo, que certamente o caminho não será o das normas, rotinas e soluções mas um caminho de busca constante que contemple a essência do vivenciar dos pais e que procuramos desvelar nesse sentido.

\section{REFERÊNCIAS BIBLIOGRÅFICAS}

1 BOEMER, M.R., VALLE, E.R.M. DO. - O significado do cuidar de crianças com câncer - visão de enfermeiras. Rev. Bras. Enf., 41 (1): 56-63, 1988.

2 KNUDSON, A.G., NAT TERSON, J.M. - Participation of parients in the hospital can of fatally ill children. Pediatrics, 26: 482-490, Sep. 1960.

3 LIMA, R.A.G. DE - O processo de trabalho da enfermagem na assistência à criança com câncer: análise das transformaçōes em um hospital-escola. Ribeiräo Preto, 1990, 124p. Dissertação de (Mestrado). Escola de Enfermagem de Ribeirão Preto-USP.
4 MAR TINS, J., B ICUDO, N.A.V. - A pesquisa qualitativa em psicologia: fundomentos e recursos básicos, São Paulo: Moraes, 1989.

5 MAR TINS, J. e cols. A fenomenologia como alternativa metodológica para pesquisa: algumas consideraçōes. Rev . Esc. Enf. USP, Sẫo Paulo, 24 (1): 139-147, abr. 1990.

6 VALLE, E.R.M. DO. - Ser-no-mundo-com o filho portador de Cancer: hermenêutica de discursos dos pais. São Paulo, 1988, 123p. Tese (Doutorado), Instituto de Psicologia da Universidade de São Paulo.

\section{ASSOCIE-SE A ABEn NO SEU ESTADO}

